\title{
A ESCRITURA BIOGRAFEMÁTICA EM O IRMÃO ALEMÃO: RASTROS DE LEITURAS NA AUTOFICÇÃO BUARQUIANA
}

\author{
Juliane de Sousa Elesbão \\ Doutoranda em Letras pela UERJ \\ julianeelesbao@gmail.com
}

\section{RESUMO}

Com base na autoficção como recurso artístico-literário para a ficcionalização de si e no conceito de biografema, propomos neste trabalho uma leitura da narrativa buarquiana $O$ irmão alemão publicada em 2014. Através dos rastros de leituras identificados no decorrer da narrativa, e do modo como a literatura funciona como mediadora entre o protagonista, o Ciccio, e os demais personagens do romance referido, objetivamos mostrar que as problematizações manifestadas em 0 irmão alemão ultrapassam o acontecimento tido como principal do enredo: a descoberta de e a busca por um meio-irmão alemão de Ciccio. Sendo assim, ficção, realidade e autor, por exemplo, são instâncias colocadas sob reflexão na escritura de Chico Buarque.

Palavras-chave: Literatura Brasileira, Metaficção, Autoficção.

\begin{abstract}
Based on the autofiction as an artistic, literary resource for fictionalization of the self and the concept of biographeme, we propose a reading of the Buarquian narrative My German Brother, published in 2014. Through the traces of texts identified in the course of the narrative and the way literature works as mediator between the protagonist, Ciccio, and the other characters of the novel, we aim to show that the problematization manifested in My German Brother goes beyond the main event of the plot: the discovery of and the search for Cicio's German half-brother. Thus, fiction, reality and author, by example, are instances of reflection in the writing of Chico Buarque.
\end{abstract}

Keywords: Brazilian Literature, Metafiction, Autofiction.

\section{CONSIDERAÇÕES INICIAIS}

Inicialmente "inventado" pelo teórico e escritor francês Serge Doubrovski, ilustrado pelo seu romance Fils, de 1977, o termo "autoficção" causou, e ainda causa, muitas controvérsias, especialmente na sua inscrição como gênero literário. Experiência, memória, 
imagens, histórias pessoais, entre outros elementos, permeiam a tessitura autoficcional, e o leitor se depara com um texto híbrido, que transita entre a autobiografia e a ficção, sem conseguir medir o que isso significa ou sobre o que se trata. Vê-se persistir uma "confusão conceitual" que impede "uma formulação mínima, consensual, para servir de diretriz na pesquisa sobre autoficção" (FAEDRICH, 2015, p. 45). Ainda assim, cabe destacar uma definição defendida pelo próprio Doubrovski acerca do que seja a autoficção. Segundo ele,

[A autoficção] é uma variante pós-moderna da autobiografia, na medida em que se desprende de uma verdade literal, de uma referência indubitável, de um discurso historicamente coerente, apresentando-se como uma reconstrução arbitrária e literária de fragmentos esparsos da memória. (VILAIN, 2005 apud FIGUEIREDO, 2013, p. 62).

Essa sustentação teórica tenta dar conta de uma exploração da subjetividade calcada na ambiguidade - "característica fundamental de uma autoficção" (FAEDRICH, 2015, p. 49) , na fragmentação em prol de um primado da narrativa. O termo autoficção acaba por contextualizar as escritas de si fundadas num "pacto" ficcional, de verossimilhança, visto que não somente o texto deve se apresentar como autoficcional; o leitor também deve reconhecê-lo como tal. Tal exploração desencadeia um conjunto de "novas" técnicas de narração que permitem ao leitor um contato mais direto com o autor-narrador/personagem, já que o escritor também se coloca como objeto da narrativa, mas não da mesma forma que na autobiografia. Essa distinção faz-se necessária, pois "I'autofiction ne peut être définie que par une critique de l'autobiographie. Il constitue un genre littéraire en opposant le genre dont il dérive et avec lequel il risque d'être confondu" (GASPARINI, 2016, p. 191). 
O próprio gênero autobiográfico sofre variações nas formas através das quais se manifesta, além de ter seu principal pressuposto - a existência de um eu real por trás da escrita autobiográfica, ou seja, o eu real corresponde ao eu biográfico - posto em xeque. Aí reside uma das principais divergências entre os dois gêneros. Na autoficção, o eu-autor se coloca na tessitura textual ficcionalizado, em que se reconhece aí a ambivalência do sujeito e o entrelaçamento entre os discursos referencial e ficcional, mas sem a exigência de um pacto de verdade com o leitor. O sujeito se insere, se reinscreve, como personagem literária, como um eu textual que "põe em cena um eu ausente, e cobre seu rosto com essa máscara" (SARLO, 2007, p. 31). Além disso, os pequenos detalhes de um indivíduo, os seus biografemas, também contribuem para a composição autoficcional, haja vista que se constituem como elementos que ligam a obra à vida do autor, indicando as possíveis correspondências que entre essas duas instâncias podem se apresentar.

Deter-nos-emos no romance O irmão alemão, de Chico Buarque, publicado em 2014. Nesse livro, conhecemos Francisco de Hollander, apelidado de Ciccio, um personagem que, assim como o autor, possui um irmão alemão "perdido", conhecido como Serge Ernst, e objetiva encontrá-lo. Nascido na cidade de São Paulo, Ciccio é filho de Sérgio de Hollander, intelectual casado com uma italiana, e possui um irmão com quem se compara constantemente no decorrer da narrativa. Entre o personagem e o escritor há algumas "coincidências": o pai intelectual, o fato de viverem as barbáries da ditadura, o gosto pelo futebol desde garotos, a alegria de se exibirem com exemplares raros saqueados da biblioteca do pai, um irmão alemão desconhecido, o fato de os dois terem se tornado escritores, entre outras. 
Destacamos, no entanto, os vários títulos e escritores literários citados e que atravessam a escritura buarquiana n'O irmão alemão. Acreditamos que esses rastros de leitura que permeiam a obra podem ser considerados como biografemas do escritor, considerando que este viveu imerso em um ambiente com muitos livros por conta do pai, o historiador, jornalista e crítico literário Sérgio Buarque de Holanda. Através da memória do personagem-narrador, observamos a conjugação de alguns fatos conhecidos da biografia de Chico Buarque com trechos fictícios. Nesse entremeio, é possível verificar leituras e autores citados que podem passar despercebidos numa primeira leitura, mas que são bastante significativos, tanto para compreender o personagem que narra a história, e a relação que este mantém com os demais personagens, quanto para que a persona do escritor se dê a conhecer. Dessa forma, não seria equívoco identificar certa complexidade que alimenta a obra, tornando-a mais do que uma testemunha de uma vida a ser grafada, e sim "um misto instável de fabulação e experiência viva" (RICOEUR, 1991, p. 191).

\section{UMA ESCRITURA BIOGRAFEMÁTICA EM O IRMÃO ALEMÃO}

A expectativa gerada em torno do último livro publicado pelo cantor e compositor Chico Buarque parece ter sido demasiada, visto que ele, por ser quem é, estaria radicalizando o intercâmbio entre vida e literatura, lançando mão da própria biografia como matéria-prima literária. Criou-se, então, em torno da obra uma necessidade coletiva de buscar "verdades" referentes à figura de Chico Buarque. Vale destacar, sobretudo, a nota presente entre os dados técnicos do livro que valida a ficcionalidade do enredo: "Os personagens e as situações desta obra são reais apenas no universo da ficção; não se referem a pessoas e fatos concretos, e não emitem opinião sobre eles". Tal nota é válida porque "[n]a autoficção, um romance pode simular ser uma autobiografia ou camuflar, com 
ambiguidades, um relato autobiográfico sob a denominação de romance" (FAEDRICH, 2015, p. 47, grifo da autora).

Partindo para uma análise mais detida da obra em análise, destacamos um ensaio crítico publicado no jornal Folha de S. Paulo, em novembro de 2014, escrito pelo professor e crítico literário Alcir Pécora que, já no título do seu texto, categoriza $O$ irmão alemão como uma "autoficção insossa" por conta das "armadilhas fatais" que desarticulam a trama: desajuste entre o tom picaresco dado à narração e os estereótipos caricaturais que compõem alguns personagens; certo "realismo postiço" que se configura como uma listagem nostálgica de ruas, bares, carros, entre outros, que não conseguem apresentar uma imagem mais convincente da época; a sobreposição dos relatos pessoais e da "obsessão frívola" de busca em detrimento da violência histórica, dada a conjuntura política do período ditatorial colocado como pano de fundo para o enredo da obra. Além disso, o referido crítico ainda afirma que: "A biblioteca do pai [de Chico Buarque] [virou] então uma listagem de livros cujos enigmas não apontam para nada, a não ser um culturalismo genérico, anódino" (PÉCORA, 2014).

O que se deve entender, a princípio, é que as narrativas autoficcionais reformulam o conceito de realidade e, por isso, não podem ser lidas como mero "realismo". Muito mais que buscar revelar detalhes da vida do autor na obra, o que se deve ter em mente é o como a vida foi filtrada pela ficção na tessitura da história. Fatos concretos foram necessários para que Chico empreendesse a escrita de tal livro - não é à toa que um historiador e um museólogo foram solicitados pelo editor da Companhia das Letras para recolher mais 
informações sobre o meio-irmão alemão que o artista sabia ter existido. Contudo, tais fatos foram ficcionalizados para compor uma narrativa que medita sobre a linha tênue entre realidade e ficção, conforme traduz o jornalista e crítico José Castello, em uma crítica publicada também em novembro de 2014:

Essa é a grande armadilha da literatura - que Chico (mas será ele mesmo?) manobra com destreza. Como uma dobradiça, o romance se desdobra em duas chapas de tamanho e forma semelhante - ora encaixado em fatos, nomes e documentos que prometem o real, ora erguido sobre as sombras não menos verdadeiras da imaginação. (CASTELLO, 2014).

De um lado, temos o que sucedeu, os vestígios de uma situação pertencente à realidade empírica, remetendo-nos ao que seria "verdade"; do outro, a possibilidade do que poderia ter sido, a criação de uma outra realidade verossímil, já que tudo n'O irmão alemão é narrado por um personagem de ficção. É notória, ainda, a atmosfera de projeções, desentendimentos e devaneios, na qual Ciccio se encontra enebriado: a narrativa se dá entre lembranças e especulações, imagens e pistas em meio aos acontecimentos que se sucedem. Tudo isso sustenta a "dobradiça" que caracteriza o romance buarquiano.

Embora haja certa identificação onomástica entre o autor e o personagem-narrador, são perceptíveis as nuanças que destoam um do outro: o Francisco da obra cursou Letras; Chico, o escritor, cursou Arquitetura; este é mais conhecido pela sua atuação no cenário artístico-musical, aquele afirma categoricamente ser professor de português - "desculpeme, o senhor é músico? Não, respondo, sou professor de literatura" (BUARQUE, 2014, p. 218) -, entre outras diferenças. Partiremos, no entanto, de um ponto em comum entre vida e obra, a influência dos livros na formação do indivíduo, vendo-os como biografemas. Estes 
se configuram como signos da individualidade do escritor e que permitem ao leitor ir além da interpretação que identifica a vida do autor no texto, mesmo que exista alguma referência.

Dessa forma, na autoficção temos a prática de uma escritura, que contorna significados distintos somados a um toque artístico, estando entre a horizontalidade da língua e a verticalidade do estilo (BARTHES, 2004, p. 11); logo, sua ênfase recai sobre o próprio criar, sobre os procedimentos de escrita, sobre a própria escritura. Enfim, para Barthes, segundo afirma Leyla Perrone-Moisés (1978, p. 35), a escritura é "um conjunto de traços que permitem distinguir, em determinados textos, um aspecto propriamente indefinível como uma totalidade". Esses traços estão ligados ao autor, são sua expressão pulsional no gesto da escrita; têm raízes nos mitos, nas representações, na história do escritor, delineando, assim, sua identidade artística. Ademais, um sujeito coloca-se em autoanálise na reinvenção do seu relato, a fim de poder adquirir um olhar narrativo sobre si mesmo.

Sabemos que a atividade da escrita não é independente da subjetividade criadora, haja vista que a manifestação desta não se dá num terreno neutro e estável - o da linguagem -, sem o filtro do espírito altamente complexo do autor no que diz respeito à sua própria pertinência existencial. Essa "filtragem" ocorre por meio da percepção do escritor, que o leva a mover suas expectativas e experiências sensíveis chamando-as para uma ressignificação e para um aprofundamento na escritura literária.

A literatura, portanto, está vinculada ao âmbito pessoal do escritor, visto que ela “como configuração institucional condiciona os comportamentos, mas, para criar, o escritor 
deve explorar esse condicionamento e interferir nele. As obras emergem em percursos biográficos singulares [...]" (MAINGUENEAU, 2001, p. 45). A organicidade interna da obra, além dos componentes linguísticos, estilísticos, de gênero, também é nutrida do que lhe é exterior e do que atinge o escritor enquanto sujeito. A literatura convive com o meio social e obriga os escritores a alimentar-se de lugares, grupos e comportamentos desse meio. No entanto, esses elementos são pensados, aprofundados na escritura literária e surtem efeitos, quando na leitura, na sua trajetória de volta para a realidade exterior à literatura.

Portanto, parece-nos pertinente investigar tal relação que avalia a existência humana de um autor em suas complexas conexões com os outros e com o mundo por meio da sua produção literária, haja vista que uma visão artística do mundo é forjada, e isso, de alguma forma, movimenta o conhecimento do homem sobre si, inquietando-o.

Por outro lado, o produto da atividade de escrita literária, a obra, sempre parece transcender a essa instância subjetiva, ao seu próprio "contexto" de criação, pela maneira como ela o exprime: a identificação problemática entre as palavras e as coisas, ou, no caso da autoficção, entre autor e personagem, a articulação entre a palavra e outras enunciações a ela ligadas, a renúncia à expressão do que é indizível, entre outros aspectos. Em outras palavras, "a literatura é a transcendência pela linguagem de uma vida empírica ou do que nomeamos realidade" (HATOUN, 2006), isto é, a linguagem literária leva o sujeito a um horizonte mais amplo que sua existência, ancorado numa imanência do sujeito a si mesmo.

Aí atua o biografema, esse pormenor que vem do autor, mas que não se limita a ser referência de uma natureza extratextual, marcando, assim, a singularidade de uma ausência. 
Está nele o lugar de "alguns gostos, de algumas inflexões", e cabe ao leitor a responsabilidade de recuperá-los como tal sem conduzi-los a relações de causalidade.

Na sua narrativa, Chico Buarque se permite ressignificar ao se aventurar na linguagem autoficcional. O autor manipula dados da realidade, "que traz[em] as marcas do verdadeiro sob a forma de rastros e vestígios" (RANCIÈRE, 2005, p. 57), e usa-os na especulação sobre a relação entre a realidade e a ficção. O biografema surge, então, na narrativa desviado de sua função de informar sobre os fatos vividos pelo escritor, apesar de partir deles, como nos faz inferir Leyla Perrone-Moisés (1983, p. 10): “o próprio saber dos biografemas depende de uma prévia informação". A relação desse tipo de elemento com a escrita autoficcional, e com a memória, dar-se-á no deslocamento do eu para um ele. Neste será depositado aquele detalhe íntimo do autor, um índice recuperável como um simples "plural de encantos". Ademais, depois que extrapola a fronteira entre a realidade e a ficção, "o autor retorna não como garantia última de verdade empírica e sim apenas como provocação, na forma de um jogo que brinca com a noção do sujeito real" (KLINGER, 2007, p. 44).

Assim, a partir dos índices referentes às leituras que são citadas no decorrer da obra, podemos entender o modo como elas se encontram imbricadas na formação intelectual de Chico Buarque e dialogadas na sua escrita. No romance, são os livros que sustentam as paredes da casa da família de Ciccio, onde se multiplicam à medida que crescem as leituras de seu pai. O protagonista tenta se aproximar da figura paterna ausente $\overline{\bar{j}}_{\overline{\mathrm{j}}}$ justamente $_{\overline{\bar{T}}}$ através das brochuras que habitam o seio familiar. Na verdade, sua relação com os demais é mediada pelos livros. 
Tudo começa pelo pai de Ciccio, que vivia enterrado em seu escritório cercado pelos livros. A rotina do lar fictício dá mostras do fascínio que o escritor Chico Buarque tem pelos livros, sobretudo os clássicos da literatura universal, usados também na tentativa de aproximação da figura paterna na vida real:

Na verdade, quando eu era criança não sabia o que meu pai fazia. Só sei que ele trabalhava de janelas fechadas e porta aberta. Eu não entrava no escritório dele. [...], para mim, lá era o território sagrado dele. [...] A partir da adolescência eu comecei a entrar no escritório dele, e a minha entrada foi pela porta da literatura. Ele não impunha nada, isso nunca. Mas a presença dele, daqueles livros todos, de certa forma despertavam curiosidade na gente. A maneira de eu me aproximar mais dele talvez tenha sido através da literatura. Então, já com meus 17 anos, não sei bem quando eu comecei a ler mais... Eu ia lá e perguntava. E ele me indicava isso, aquilo... [...] E me perguntei: eu estava mesmo interessado na literatura, ou interessado, através da literatura, em me afirmar diante do meu pai? (CUNHA JR., 1992, p. 6).

E no romance:

[...] quando porventura ele se interessava por alguma novidade, sempre encontrava um pormenor que o remetia a antigas leituras. Então chamava com seu vozeirão: “Assunta! Assunta!, e lá ia minha mãe atrás de um Homero, um Virgílio, um Dante, que Ihe trazia correndo antes que ele perdesse a pista. E a novidade ficava de lado enquanto ele não relesse o livro antigo de cabo a rabo. (BUARQUE, 2014, p. 19).

Esses detalhes se inserem na escrita da obra como biografemas, como um punctum, aquilo que deveria atingir quem lê de forma a arrebatá-lo ou que pode ser visto, por um leitor mais atento, como a metonímia para a narração de uma vida. Tais detalhes mereceriam mais destaque na obra, mais até do que a busca incansável que Ciccio 
empreende pelo meio-irmão alemão, confundida com a situação vivida por Chico Buarque, pois é a partir daqueles que toda a trama começa. Na tentativa desesperada de se aproximar da figura paterna, o protagonista invade a biblioteca e somente inicia suas investigações após encontrar uma carta da alemã Anne Ernst - um amor vivido por Sérgio de Hollander numa temporada em Berlim - ao prosseguir na leitura de um dos livros do pai. Tal situação abre a obra $O$ irmão alemão com uma espécie de catalogação afetiva:

Asa de inseto, nota de dez mil-réis, cartão de visita, recorte de jornal, papelzinho com garranchos, recibo da farmácia, bula de sonífero, de sedativo, de analgésico, de antigripal, de composto de alcachofra, há de tudo ali dentro. E cinzas, sacudir um livro do meu pai é como soprar um cinzeiro. Desta vez eu vinha lendo O Ramo de Ouro, numa edição inglesa de 1922, e ao virar a página 35 dei com uma carta endereçada a Sergio de Hollander, rua Maria Angélica, 39, Rio de Janeiro, Südamerika, tendo como remetente Anne Ernst, Fasanenstrasse 22, Berlin. (BUARQUE, 2014, p. 8).

Um clássico da antropologia, em língua inglesa, é a testemunha daquilo que será tão caro ao protagonista, e não poderia ser outro livro, conforme esclarece o professor Georg Otte:

O título do livro de Frazer [O Ramo de Ouro] remonta à Eneida, de Virgílio, em que um ramo de ouro abre ao herói o acesso ao Hades. Para Ciccio, o Ramo de ouro abre o acesso não exatamente ao mundo inferior do pai, mas a um mundo escondido - ou pelo menos silenciado - na vida dele. Entre asas de inseto, bulas de diversos remédios e as cinzas de cigarro, entre os "restos" do pai, ele encontra a carta que não apenas permite a Ciccio reconstituir, "benjaminianamente", parte da vida do pai, mas ainda fantasiar um irmão distante que, pela distância, Ihe permite todo tipo de devaneio [...]. (OTTE, 2016, p. 199). 
Assim, temos que esses biografemas, ou os "restos", vão compondo um jogo de analogias em que as limitações do real são expostas por não conseguir concorrer com a ficção. Além disso, os vários autores que são citados na obra e o próprio ato da leitura, tomados como estratégias pelo Ciccio para "se chegar" ao pai e ganhar a sua predileção, nos oferecerão um olhar disperso e fragmentário de um sujeito em constante construção. Em outras palavras, encontrar um meio-irmão desconhecido também contribui para o autoconhecimento do próprio Ciccio; por outro lado, atentar para a biblioteca de Sérgio Buarque de Holanda - o da vida real -, explorada na literatura buarquiana, é dar conta de um íntimo muito mais significativo para o referido autoconhecimento do alter ego de Chico.

Ademais, essas leituras biografemáticas estão no entremeio das relações interpessoais do protagonista com os demais personagens: a mãe é quem organiza a biblioteca do marido; ao irmão, Mimmo, é permitido ter acesso aos livros do pai, como um "guardião do santuário", mas ele restringe-se a ler gibis, o que incomoda Ciccio; este fica a imaginar o leitor que talvez seu meio-irmão alemão seja, além de usar sonetos shakespearianos para se aproximar das ex-namoradinhas de Mimmo; é através de obras de Céline e Camus que Ciccio consegue se relacionar com uma colega do curso de Letras, a Maria Helena, por quem se enamorara; confundido inicialmente com o irmão alemão, Christian - filho de um pianista - é sempre visto por Ciccio abarrotado de livros e surrupia deste uma obra de Rimbaud, entre outros fatos.

No que diz respeito à sexualidade do personagem-narrador, vemos que ela também se manifesta na relação que ele possui com as brochuras da biblioteca do pai: "durante toda a minha infância mantive essa ligação sensual com os livros" (BUARQUE, 2014, p. 16). 
Acrescente-se a percepção de que havia "algo de erótico em separar dois livros apertados, com um anular e o indicador, para forçar a entrada de $\mathrm{O}$ Ramo de Ouro na fresta que Ihe cabe" (BUARQUE, 2014, p. 10). Possuir os livros dessa maneira seria como adquirir experiências, acumular sensações tão prazerosas quanto o sexo. Assim sendo, observamos que a literatura parece atuar como um personagem ao permear a escritura intertextual de Chico, cuja importância na formação intelectual do escritor é apresentada em sua fala:

Eu me lembro de, lá pelos 18 anos, ir para a Faculdade de Arquitetura com esses livros em francês, o que era uma atitude um pouquinho esnobe. Talvez para me valorizar dentro de casa ou talvez para agradar meu pai (...) até que um colega me deu uma debochada: 'mas você só vem com esses livros para cá, porque não lê literatura brasileira? Eu respondi: 'você tem razão'. E comecei a ler o que não havia lido até então, de Mario de Andrade, Oswald de Andrade até Guimarães Rosa, por quem me apaixonei. Guimarães Rosa talvez seja esse marco para mim. (FERNANDES, 2009, p. 25).

Tal declaração chega a coincidir com a seguinte atitude do protagonista do romance buarquiano:

Gabola, gabarola, cabotino, meus colegas não me perdoavam por ostentar os livros autografados por meu pai nos corredores da faculdade de letras. $E$ arriscando-me a aborrecê-los mais um pouco, eu não resistia em me referir sem cerimônia aos autores assíduos da minha casa, o João, o Jorge, o Carlos, o Manuel. O Sartre? De passagem por São Paulo fez questão de nos visitar com a Simone, extrapolei numa aula de filosofia. (BUARQUE, 2014, p. 47).

As referências literárias desdobram-se na narrativa como a desnudar o protagonista, conduzindo-o em trilhas diversas e mediando sua relação com os outros, o que funcionará como um propulsor autorreflexivo e metaficcional, com o qual o narrador comentará, em 
alguns momentos, sobre o processo de ficcionalização como se estivesse a escrever um livro, um romance, no qual seria também um personagem:

[...] serei capaz de escrever um romance inspirado na Alemanha dos anos 30, tão presente nas minhas leituras e fantasias. Posso romancear por exemplo a história de Anne Ernst, cuja foto com meu irmão no colo guardo no bolso da camisa e várias vezes por dia tenho a compulsão de olhar. (BUARQUE, 2014, p. 148).

[...] me incentivaria a investir por exemplo num romance de formação, em que eu tratasse da minha infância conturbada, dos meus conflitos familiares, dos meus impasses sentimentais. (BUARQUE, 2014, p. 173).

Logo, a busca pelo irmão se confunde com a escrita autoficcional, construída na relação do autor/narrador com o mundo da leitura, da literatura. Essa escrita, também metaficcional, imprime em si mesma uma identidade literária, narrativa. Esses apontamentos sobre a própria construção de um romance balizam a narrativa, já que se volta para o seu próprio funcionamento, e remetem para um sujeito-escritor em processo, especialmente se considerarmos que tais reflexões metaficcionais indagam um eu que se constrói sempre em paralelo ao outro.

Poderíamos destacar, ainda, um fato inusitado que, aparentemente, parece não dizer nada: enquanto o protagonista encontra-se "entretido na cama" com a Dra. Natércia, "que era bastante próxima da reitoria da Universidade de São Paulo", um Dom Quixote tomba no chão sem nenhum motivo específico para a sua queda. A mulher, amedrontada, afirma que tal fato é coisa do Mimmo, o irmão desparecido de Ciccio; este se mostra indiferente para com o livro caído (BUARQUE, 2014, p. 194-195). No entanto, nós, leitores, não podemos esquecer que aquele livro, considerado o primeiro romance da literatura ocidental, também 
lida com o jogo da realidade e da ficção, no qual literatura e vida parecem tornar-se indistintas. Os dois planos se implicam, assim como na autoficcção buarquiana. 0 personagem narrador d'O irmão alemão mostra-se, ao mesmo tempo, autor e leitor da própria existência, bem como ocorre com o fidalgo Quixote, de Cervantes; logo, por mais que tratemos de dois textos completamente diferentes entre si, sobretudo pelo intervalo de mais de quatrocentos anos que os distancia, o que está em jogo é essa difícil conciliação entre ficção e realidade. Esse biografema, o romance de Cervantes, ainda contribui para a atmosfera metaficcional que permeia a obra de Chico Buarque, já que vemos problematizados todos esses conceitos que vínhamos acentuando (ficção, realidade, autor).

Dessa forma, é corroborada a ambiguidade subjetiva própria da autoficção e o afastamento de si necessário para o autoentendimento tanto do personagem, que se torna escritor, quanto do escritor, que se coloca como personagem.

\section{CONSIDERAÇÕES FINAIS}

A intenção desta leitura é colocar o intertexto como mais um operador ativo na autoficção, podendo auxiliar na compreensão da presença do autor em seu texto. Temos um personagem que se fragmenta em suas leituras; logo, só pode ser apreendido através delas. De um modo mais geral, a ideia totalizadora de centro é superada pela noção do homem fragmentado tão convergente com a pós-modernidade por nós vivenciada e refletida na literatura contemporânea, pois, conforme Dubrovski (2011, p. 22): “la conception même du sujet a changé. D’unité à travers le récit, il est devenu brisé, morcelé, fragmentaire, à la limite incohérent". Tal fato contribuirá para demarcar também a diferença entre as categorias autobiografia e autoficção, já que a primeira procura se aproximar do vivido, 
buscando ser: "elle [l'autobiographie classique] sera donc chronologique et logique, elle s'efforcera, malgré les lacunes inévitables de la mémoire, de suivre le déroulement d'une vie [...]" (DOUBROVSKI, 2011, p. 22).

Assim, revestidos como biografemas, os indícios de leituras que marcam $O$ irmão alemão fazem com que o texto literário se destaque em primeiro plano em relação à biografia do autor, pois deste não é exigido prestar contas de toda a história da sua vida, apesar de sabermos da formação literária do compositor influenciada, especialmente, pelo pai. Parece-nos, então, injusta a conclusão de Alcir Pécora anteriormente referida. Os vários títulos e autores citados no decorrer da narrativa buarquiana são usados para recriar uma existência e dão mostras de uma dispersão do sujeito na composição autoficcional, que tenta "juntar fragmentos de um mundo em constante mutação" (PARO, 1990, p. 198). A partir daí, a referencialidade possibilitada pela escritura biografemática de Chico Buarque põe em questionamento os limites entre ficção e realidade, considerando a projeção do autor na escrita e a construção do ser ficcional. Ademais, o personagem-escritor toca o escritor-personagem justamente por meio das obras e dos autores clássicos referendados na narrativa d'O irmão alemão. De todo modo, não devemos esquecer que a obra em análise é ficção, sobretudo, porque a matéria biográfica é usada apenas como estratégia literária e foge ao alcance do escritor a partir do momento em que se materializa em uma obra e passa para as mãos do leitor.

Esses "traços biográficos" contribuem para demarcar a ambiguidade que também caracteriza o gênero autoficcional, bem como ocupam no texto o lugar do autor por atrair a percepção do leitor, mudando o foco da leitura. Por isso a afirmação presente no tópico 
anterior deste artigo: a presença das leituras na obra de Chico Buarque tem importância mais significativa do que a busca que Ciccio empreende pelo irmão alemão. Esses biografemas ultrapassam, portanto, certa representação de um passado vivido, haja vista estarem abertos à criação, pois apontam para vazios, lacunas que convidam o leitor a compor um outro texto a partir daquele, conduzindo-o no jogo autoficcional que Chico Buarque trama com destreza.

\section{REFERÊNCIAS}

BARROS, Maria Heloisa Noronha. Miguilim e Manuelzão. Viagem para o Ser. 1988. Dissertação (Mestrado em Filosofia) - Departamento de Filosofia da Faculdade de Filosofia e Ciências Humanas, Universidade Federal de Minas Gerais, Belo Horizonte, 1988.

BARTHES, Roland. O grau zero da escrita: seguido de novos ensaios críticos. Trad. Mario Laranjeira. 2. ed. São Paulo: Martins Fontes, 2004. (Coleção Roland Barthes).

BUARQUE, Chico. O irmão alemão. São Paulo: Companhia das Letras, 2014.

CUNHA JR., M. Chico Buarque fala sobre seu pai. Folha de São Paulo, São Paulo, jul. 1992. Entrevista concedida a Melquíades Cunha Júnior. Mais!, p. 6.

CASTELLO, José. Crítica: 'O irmão alemão' vai ao limite de uma busca alucinante. O Globo, Rio de Janeiro, 15 novembro 2014. Disponível em: http://oglobo.globo.com/cultura/livros/critica-irmao-alemao-vai-ao-limite-de-uma-busca-alucinante14564813. Acesso em: 15 de nov. 2016.

DOSSE, François. O Desafio Biográfico. São Paulo: Editora da Universidade de São Paulo, 2009.

DOUBROVSKI, Serge. C'est fini. Entretien réalisé par Isabelle Grell. In: FOREST, Philippe. La Nouvelle Revue Française. Je \& Moi. Paris: Gallimard, № 598, octobre 2011.

FAEDRICH, Anna. O conceito de autoficção: demarcações a partir da literatura brasileira contemporânea. Revista Itinerários, Araraquara, n. 40, p. 45-60, jan/jun, 2015.

FERNANDES, Rinaldo de. Chico Buarque do Brasil. Rio de Janeiro: Garamond, 2009.

FIGUEIREDO, Eurídice. Mulheres ao espelho: autobiografia, ficção e autoficção. Rio de Janeiro: EdUERJ, 2013. 
GASPARINI, Philippe. Poétiques $d u$ je: du roman autobiographique à l'autofiction. Lyon: Presses Universitaires de Lyon, 2016.

HATOUM, Milton. Entrevista com Milton Hatoum. Digestivo Cultural, São Paulo, 1ㅇ maio 2006. Concedida a Julio Daio Borges. Disponível em: $<$ http://www.digestivocultural.com/entrevistas/entrevista.asp?codigo=1\&titulo=Milton_Hat oum>. Acesso em: 29 de outubro de 2014.

KLINGER, D. A escrita de si - o retorno do autor. In: . Escritas de si, escritas do outro: o retorno do autor e a virada etnográfica. Rio de Janeiro: 7 Letras, 2007.

MAINGUENEAU, Dominique. O contexto da obra literária. Trad. Marina Appenzeller. 2. ed. São Paulo: Martins Fontes, 2001.

OTTE, Georg. A sombra do pai - sobre O irmão alemão, de Chico Buarque. Revista Aletria, Belo Horizonte, v. 26, p. 195-200, mai/ago, 2016.

PARO, Maria Clara Bonetti. O Pós-Moderno na Literatura Americana: a Metaficção. Revista Itinerários. São Paulo: Unesp, n. 1, 1990.

PÉCORA, Alcir. Armadilhas na trama tornam livro de Chico Buarque uma autofiç̧ão insossa. Folha de São Paulo, São Paulo, 15 novembro 2014. Disponível em: http://www1.folha.uol.com.br/fsp/ilustrada/195567-armadilhas-na-trama-tornam-livro-de-chicobuarque-uma-autoficcao-insossa.shtml. Acesso em: 16 nov. 2016.

PERRONE-MOISÉS, Leyla. Roland Barthes: o saber com sabor. São Paulo: Brasiliense, 1983. . Texto, Crítica, Escritura. São Paulo: Ática, 1978.

RANCIÉRE, J. A partilha do sensível: estética e política. São Paulo: Ed. 34, 2005.

RICOEUR, Paul. O si-mesmo como um outro. Trad. Luci Moreira Cesar. Campinas: Papirus, 1991.

SARLO, Beatriz. Tempo passado: cultura da memória e guinada subjetiva. Trad. Rosa Freire d’Aguiar. São Paulo: Companhia das Letras; Belo Horizonte: UFMG, 2007.

Artigo recebido em: 26 de fevereiro de 2018. Artigo aprovado em: 01 de setembro de 2018. 